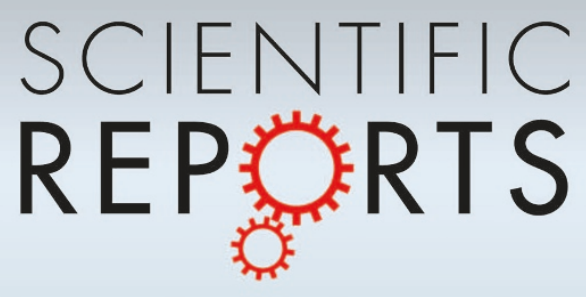

\title{
OPEN Atomic-scale decoration for improving the pitting corrosion resistance of austenitic stainless steels
}

SUBJECT AREAS:

METALS AND ALLOYS

CONDENSED-MATTER PHYSICS

MECHANICAL PROPERTIES

ENGINEERING

Received

4 September 2013

Accepted

3 December 2013

Published

8 January 2014

Correspondence and requests for materials should be addressed to X.L.M. (xlma@imr.ac.

* These authors contributed equally to this work.

$\uparrow$ Current address: Materials Physics and Applications Division, MPA-CINT, Los Alamos

National Laboratory,

Los Alamos, NM

87545, USA.

\author{
Y. T. Zhou*, B. Zhang*, S. J. Zheng†', J. Wang, X. Y. San \& X. L. Ma
}

Shenyang National Laboratory for Materials Science, Institute of Metal Research, Chinese Academy of Sciences, Wenhua Road 72, 110016 Shenyang, China.

Stainless steels are susceptible to the localized pitting corrosion that leads to a huge loss to our society. Studies in the past decades confirmed that the pitting events generally originate from the local dissolution in $\mathrm{MnS}$ inclusions which are more or less ubiquitous in stainless steels. Although a recent study indicated that endogenous $\mathrm{MnCr}_{2} \mathrm{O}_{4}$ nano-octahedra within the $\mathrm{MnS}$ medium give rise to local nano-galvanic cells which are responsible for the preferential dissolution of MnS, effective solutions of restraining the cells from viewpoint of electrochemistry are being tantalizingly searched. Here we report such a galvanic corrosion can be greatly resisted via bathing the steels in $\mathrm{Cu}^{2+}$-containing solutions. This chemical bath generates $\mathrm{Cu}_{2-\delta} \mathrm{S}$ layers on the surfaces of $\mathrm{MnS}$ inclusions, invalidating the nano-galvanic cells. Our study provides a low-cost approach via an atomic scale decoration to improve the pitting corrosion resistance of stainless steels in a volume-treated manner.

S tainless steels, widely used in industry and in our daily life, are in fact not "stainless". In the presence of aggressive anionic species, they are susceptible to the localized pitting corrosion that is one of the major causes of the materials' failure, leading to a huge loss to our society. Therefore, to clarify the origin of pitting process and to improve the pitting resistance in stainless steels has been one of the major research focuses in several disciplines such as materials science, chemistry, and metallurgy ${ }^{1-5}$.

Sulphur, particularly in austenitic stainless steels, plays critical roles in tuning the material's properties. For example, manganese sulphide (MnS) as a major existence of sulphur in stainless steels taking a role of lubricant is needed for machining and extending cutting tool life ${ }^{6}$. However, high sulphur content, and thus high volume of $\mathrm{MnS}$ in stainless steels, results in poor pitting resistance, since it is generally believed that the pitting events originate from the local dissolution of $\mathrm{MnS}^{7-11}$. Our recent studies ${ }^{12,13}$ based on high-resolution transmission electron microscopy (HRTEM) indicated that the MnS inclusion is not only compositionally inhomogeneous but also structurally dissimilar. We found that novel $\mathrm{MnCr}_{2} \mathrm{O}_{4}$ nano-octahedra embedded in the MnS medium catalyzed the local dissolution of $\mathrm{MnS}$ by the local nano-galvanic cells of $\mathrm{MnCr}_{2} \mathrm{O}_{4} / \mathrm{MnS}$. Since then, effective solutions of restraining the cells from electrochemically working have been being tantalizingly searched.

However, invalidating the cells in a low-cost and high-efficiency way has been unattainable with current treatments performed both in industry and laboratories. Usually, final annealing and the subsequent pickling performed on the finished products are the two most common processes to enhance the localized corrosion resistance of stainless steels. During the former processes, the improvement of corrosion resistance is ascribed to the oxidation of steel surface ${ }^{14}$. While the principle beneficial factor of the latter process is the removal of MnS inclusions ${ }^{15}$. Nevertheless, the crevices and residual sulphide after removal of MnS were still identified as the sensitive sites for pitting initiation ${ }^{16}$. Other particular approaches, such as eliminating the $\mathrm{MnS}$ at the steel surface by laser or high current pulsed electron beam surface treatment ${ }^{10,17,18}$ which have been tried in laboratories and to some extend enhanced the pitting resistance, are of high-cost and low-efficiency. Their applications are believed to be rather limited in volume-treated industrialized processes.

It is known that the composition of sulphide inclusions plays a critical role in the initiation of pitting corrosion of stainless steels ${ }^{19,20}$. For instance, $\mathrm{Cu}$-containing $\mathrm{MnS}$ inclusions are found to be electrochemically inactive in initiating pitting corrosion ${ }^{8}$. Besides, alloying $\mathrm{Cu}$ could eliminate the harmful sulphur species in corrosive solution by producing insoluble $\mathrm{Cu}_{2} \mathrm{~S}^{21,22}$. In the present study, we synthesized, in virtue of the cation exchange reaction ${ }^{23-26}$, a thin film of $\mathrm{Cu}_{2-\delta} \mathrm{S}$ on the exposure layer of MnS. Such chemical decoration leads to the 
inactivation of the anodic MnS inclusions and avoiding the nanogalvanic cells from electrochemically working, by which the pitting resistance of austenite stainless steels is significantly enhanced.

\section{Results}

$\mathrm{MnCr}_{2} \mathrm{O}_{4}$ nano-octahedron catalyzing local dissolution of $\mathrm{MnS}$ in stainless steels. A commercial hot-rolled $316 \mathrm{~F}$ stainless steel with high sulphur content was chosen since it provides a large number of MnS inclusions for analysis. The mechanical rolling made MnS inclusions needle-shaped and parallel to the rolling direction. Dimensions of the MnS inclusions are several tens of micrometers in length and a few hundred nanometers in diameter. MnS has a $\mathrm{NaCl}$-type structure with lattice parameter of $0.52 \mathrm{~nm}$. TEM observations were performed under the newly developed highangle-angular-dark-field (HAADF) technique, which provides strong contrast associated with the local variety of chemical composition (atomic number) and/or thickness contribution by detecting high-angle scattering electrons ${ }^{27}$. As reported in the earlier study ${ }^{12}$, the dissolution of $\mathrm{MnS}$ is strongly localized in salt water: the pit which results from the local dissolution of $\mathrm{MnS}$ always features a nano-scale undissolved core whose structure and composition are different from that of MnS. Namely, the initial site of MnS dissolution is at the periphery of a nano-particle which was embedded in MnS medium (Fig. 1a).

Based on a series of EDPs and energy dispersive X-ray spectroscopy (EDS), the nanoparticles are identified to be spinel $\mathrm{MnCr}_{2} \mathrm{O}_{4}$, or $\mathrm{Mn}(\mathrm{Cr}, \mathrm{Ti})_{2} \mathrm{O}_{4}$ if small amount of titanium is taken into account. By means of large-angle tilting experiments and 3D tomography in the TEM, we found that each of the $\mathrm{MnCr}_{2} \mathrm{O}_{4}$ nano-particles has a specific geometric shape, which was identified basically to be an octahedron enclosed by eight triangles. The 3D morphology of an octahedron is displayed in Fig. $1 \mathrm{~b}$ where each of the $\{111\}$ planes is alternately exhibited. It is worthwhile to mention that not all the $\mathrm{MnCr}_{2} \mathrm{O}_{4}$ nano-particles feature a regular octahedron-shaped, as that shown in our previous study. In some cases, they are octahedron but with remarkable distortion, shown in Fig. 1b. This indicates that

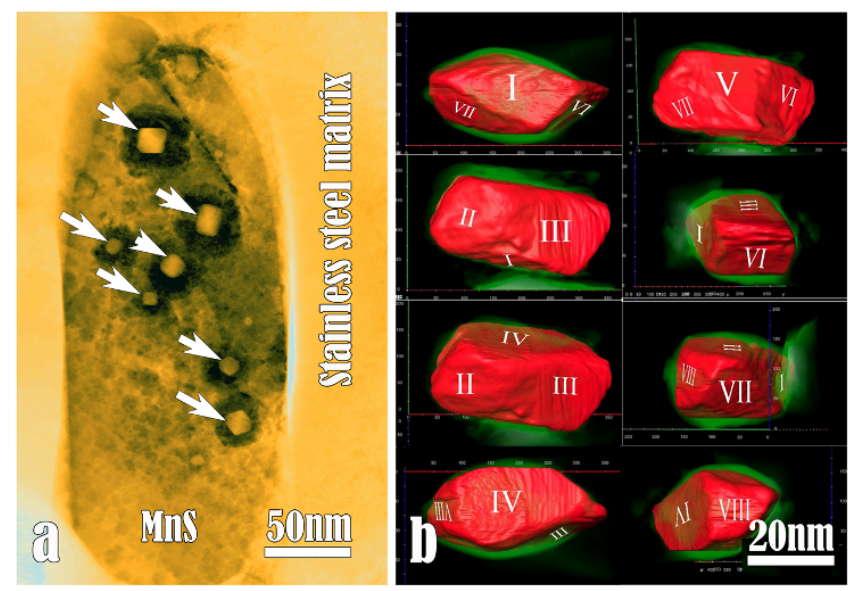

Figure 1 Identification of nano-octahedra as the initial sites where $\mathrm{MnS}$ starts to be dissolved. (a) A HAADF image showing the $\mathrm{MnCr}_{2} \mathrm{O}_{4}$ nanoparticles (arrowed) catalyzed the local dissolution of a MnS inclusion section. Extensive studies based on various TEM techniques indicated that a single MnS inclusion is compositionally inhomogeneous and structurally dissimilar. Usually in each $\mathrm{MnS}$ inclusion, a number of $\mathrm{MnCr}_{2} \mathrm{O}_{4}$ nanoparticles are embedded, and each oxide particle acts as a "tumour" making MnS locally be dissolved. (b) Determination of octahedron by 3D tomography technique. Each of the oxide particle has an octahedron configuration enclosed by eight $\{111\}$ planes which are labeled with I, II, III, ... VIII, respectively. the detailed atomic configurations at the octahedron surface are quite complicated.

The spinel $\mathrm{MnCr}_{2} \mathrm{O}_{4}$ particles shown here, although they are as fine as nano-meter scale, are present in almost all the $\mathrm{MnS}$ inclusions. So far, little attention has been paid to the ultra-fine inclusions in stainless steels, which is based on the cognition that they do not undermine the mechanical properties of the steels. However, the nano-sized oxide particles shown above are found to play a critical chemical role in catalyzing $\mathrm{MnS}$ dissolution and pitting corrosion of the steels.

Chemical modification improving the pitting resistance. The chemical modification of MnS inclusions was performed by immersing the polished stainless steel sheets in a dilute $\mathrm{CuSO}_{4}$ solution at room temperature. The electron-probe X-ray microanalysis (EPMA) experiment clearly reveals that the cation exchange reaction has taken place during the immersion, namely, $\mathrm{Cu}$ ions have selectively substituted some $\mathrm{Mn}^{2+}$ in $\mathrm{MnS}$ inclusions after 1 hour immersion (Fig. 2). Since the depth of characteristic X-rays produced by electrons is about one or two micrometers for the elements with medium atomic mass ${ }^{28}$, the whole $\mathrm{MnS}$ with diameter of several hundred nanometers is in the detection range of EPMA. Therefore, the co-existence of $\mathrm{Mn}$ and $\mathrm{Cu}$ signals in Fig. $2 \mathrm{~b}$ indicates that the elements replacement should happened on the skin layer of MnS. Thanks to the passive film of stainless steels, iron has no obvious replacement reaction with copper ions since we did not find any morphology or composition change on the steel matrix. The elements substitution and the thickness of reaction layer are determined by the TEM cross-sectional observation of the treated sample which provides direct information on morphology and chemical compositions after the reaction. After the bulk sample was bathed in $0.05 \mathrm{~mol} / \mathrm{L} \mathrm{CuSO}_{4}$ solution for $1 \mathrm{~h}$, a HAADF image and EDS elemental mapping of the selected area are shown in Fig. 2c. It is seen that the surface layer of MnS almost all transformed to copper sulphide. The thickness of copper sulphide layer was nearly $200 \mathrm{~nm}$. A sharp interface cannot be distinguished between manganese sulphide and copper sulphide since the reaction process was controlled by cation diffusion.

To evaluate the enhancement of pitting resistance after chemical treatment, the potentiodynamic polarization tests on untreated and treated samples were performed in $0.5 \mathrm{~mol} / \mathrm{L} \mathrm{NaCl}$ electrolyte. Some typical potentiodynamic polarization curves are shown in Fig. 3a. It can be seen that all the treated samples feature a noble shift of the open circuit potentials $\left(E_{\text {ocp }}\right)$ and pitting potential $\left(E_{p i t}\right)$ and an obvious decrease of passive current density, which indicates the chemical treatment results in an improved pitting resistance. Generally, the pitting potential data of stainless steel is scattered. To evaluate the beneficial effect of the chemical treatment in a statistic analysis, we tested many samples, including untreated and treated samples under different treating conditions. The distributions of $E_{p i t}$ values for the samples before and after different treatment were plotted as illuminated in Figs. $3 \mathrm{~b}$ and $3 \mathrm{c}$. Cumulative probability shown in the vertical was calculated by a mean rank method: $P_{\text {cum }}=i /(N+1)$, where $P_{\text {cum }}$ is the cumulative probability of measured pitting potential $\left(E_{p i t}\right), i$ is the order in the total number $N(i=1,2,3, \ldots, N)$. In Fig. $3 \mathrm{~b}$, it is found that the onset of stable pitting on the untreated samples occurs at near $230 \mathrm{mV}$, while for the samples treated in $\mathrm{CuSO}_{4}$ solution with duration from $10 \mathrm{~min}$ to $10 \mathrm{~h}$, all $E_{\text {pit }}$ shift to noble values by $100 \mathrm{mV}$ on average. The treating duration longer than half an hour seems not to have more positive effect. It is probably because the cation exchange reaction reaches the equilibrium state in 30 minutes. We have carried out systemic electrochemical tests on the samples experienced bathing in $\mathrm{CuSO}_{4}$ solution with variant concentrations, like $0.001 \mathrm{~mol} / \mathrm{L}, 0.005 \mathrm{~mol} / \mathrm{L}, 0.01 \mathrm{~mol} / \mathrm{L}, 0.05 \mathrm{~mol} / \mathrm{L}$, and $0.5 \mathrm{~mol} /$ L. The pitting potential of the samples treated in solution with different concentrations is shown in Fig. $3 \mathrm{c}$. It is seen that the $\mathrm{E}_{\text {pit }}$ values 

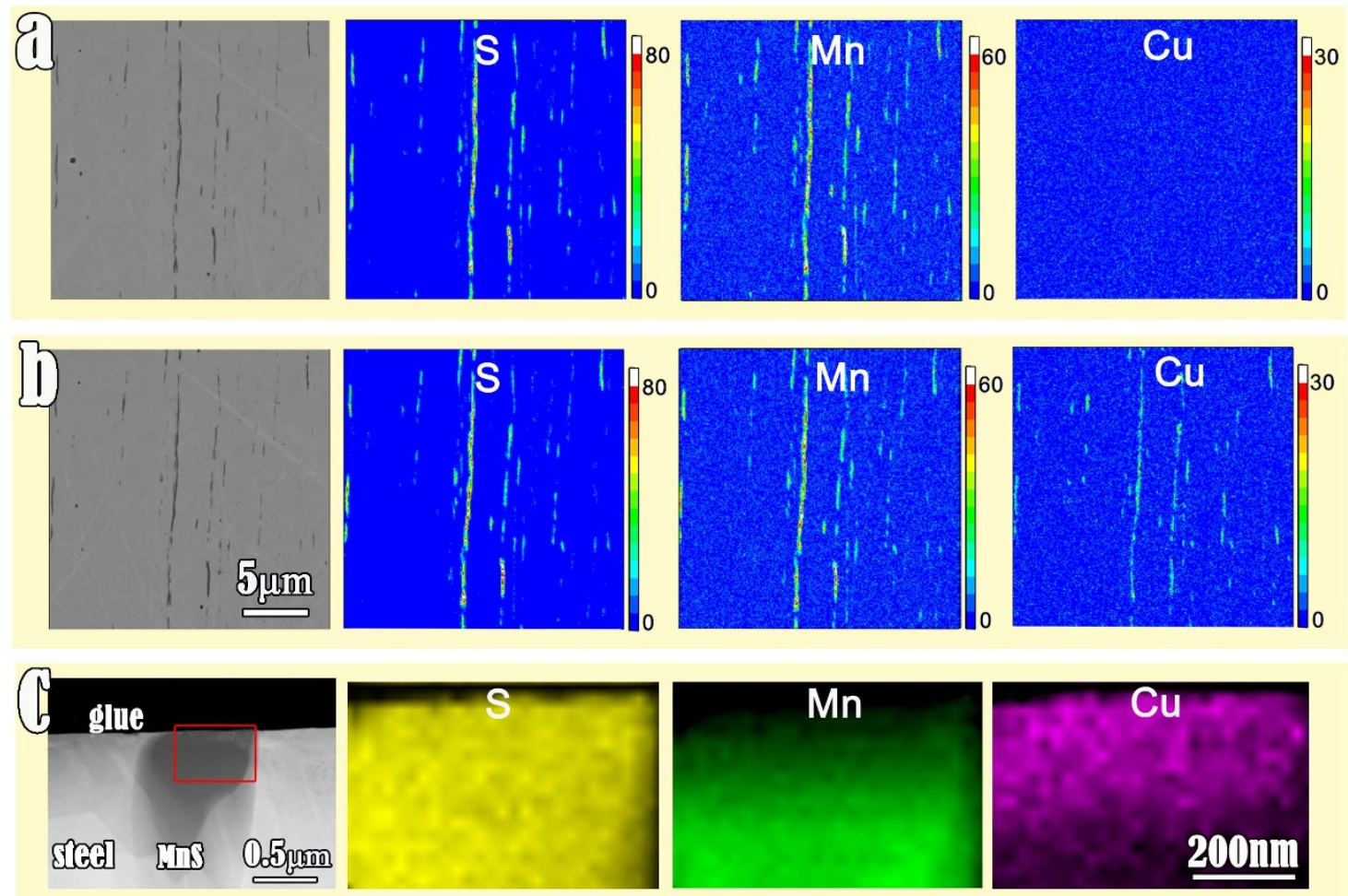

Figure $2 \mid$ The elemental distribution on the surfaces of steel samples. (a) and (b) SEM and EPMA images of the same steel sample surface before (a) and after (b) chemical modification in $0.01 \mathrm{M} \mathrm{CuSO}_{4}$ solution for one hour, respectively. According to the SEM images of the sample (a) before and (b) after chemical modification in $0.01 \mathrm{M} \mathrm{CuSO}_{4}$ solution for one hour, little difference can be identified in between. However, remarkable change of MnS inclusions can be clearly noted by comparisons of elemental maps. Except $\mathrm{Mn}$ and S, primary MnS has no signal of Cu. In contrast, after chemical modification, besides $\mathrm{Mn}$ and S, the Cu signal is visible in the "MnS inclusions". (c) cross-sectional HADDF image and EDS elemental mapping obtained in the sample treated in $0.05 \mathrm{M} \mathrm{CuSO}_{4}$ solution for $1 \mathrm{~h}$. The copper sulphide layer was about $200 \mathrm{~nm}$ thick. This composition identification indicates that cation exchange reaction occurred during chemical bath of the steel sample.

of the samples, treated in such a wide range of solution concentrations, display similar.

For comparison with other steels, the pitting potential of a commercial 316L stainless steel sample was determined which is about $320 \mathrm{mV}$ (as shown in Fig. 3d). Obviously, the chemical treatment makes $316 \mathrm{~F}$ stainless steel win an equivalent level of pitting resistance with that of 316L stainless steel, which is generally believed to have an excellent corrosion resistance.

To confirm the universality of the chemical modification, we treated the 316L stainless steel in the $\mathrm{Cu}$-containing solution and also found the treatment improved the pitting resistance as that in the $316 \mathrm{~F}$ stainless steel; for instance, the $E_{p i t}$ has a shift of nearly $100 \mathrm{mV}$ after one hour treatment. As a comparison, small pieces of 316L sample with and without visible MnS inclusions, respectively, were selected for electrochemically testing. As seen from the potentiodynamic polarization curves (Fig. 3d), the chemically modified 316L sample with MnS inclusions is very close to that of its MnSfree counterpart, which indicates that such a chemical modification make MnS inclusions inactive although the spinel nano-oxides are still there.

In addition to the $\mathrm{CuSO}_{4}$ solution, dilute $\mathrm{CuCl}_{2}$ solutions with various concentrations are also applied for the chemical modification of MnS, and almost the same enhancement is achieved as that in $\mathrm{CuSO}_{4}$ (Fig. 3e).

Chemical modification substantially lowering the pitting nucleation rate. The samples undergoing different treatments were potentiodynamically polarized to the potential above $E_{p i t}$ and the tests were terminated when the anodic current density reached the value of $1 \mathrm{~mA} / \mathrm{cm}^{2}$. Then all the samples were unloaded and examined by scanning electron microscopy (SEM). Figure 4 shows three typical SEM images of the samples suffered electrochemical tests. In the untreated sample, each $\mathrm{MnS}$ dissolves severely and a large number of pits appear in the vicinity (arrowed, in Fig. 4a). In contrast, in the sample treated in the $\mathrm{Cu}$-containing solution for 10 minutes, the number of the pits decreases dramatically (arrowed, Fig. 4b). Onehour-treatment results in a further decrease of the number of pits (Fig. 4c). Moreover, no obvious dissolution of the MnS inclusions was observed on the surfaces of treated samples even after the stable pits appeared, which indicates that the nano-galvanic cells of $\mathrm{MnCr}_{2} \mathrm{O}_{4} / \mathrm{MnS}$ have been invalided by the chemical decoration.

In order to characterize the substantial decrease of the number of pits on the chemically modified samples, the number of pits per unit length of the inclusion was statistically counted, based on over $300 \mathrm{MnS}$ inclusions in each sample (Fig. 5). The minimum number reaches 4 , approximately, on the sample experienced one hour immersion.

\section{Discussion}

The general phenomenon of $\mathrm{MnS}$ dissolution is that it happens at the interface of $\mathrm{MnS} / \mathrm{MnCr}_{2} \mathrm{O}_{4}$. The novel $\mathrm{MnCr}_{2} \mathrm{O}_{4}$ nano-octahedra embedded in the MnS medium catalyzed the local dissolution of $\mathrm{MnS}$ by the local nano-galvanic cells between them ${ }^{12,13}$. Once the dissolution process starts, the whole process goes rapidly. During the chemical modification in $\mathrm{Cu}^{2+}$-containing solution, the surface layer of MnS inclusions transforms into copper sulphide crystals, which is thought to be electrochemically inactive to initiate pitting corrosion $^{21}$.

To figure out the details of reaction products, the TEM specimens before and after immersion in a $\mathrm{CuSO}_{4}$ solution for 20 minutes were 

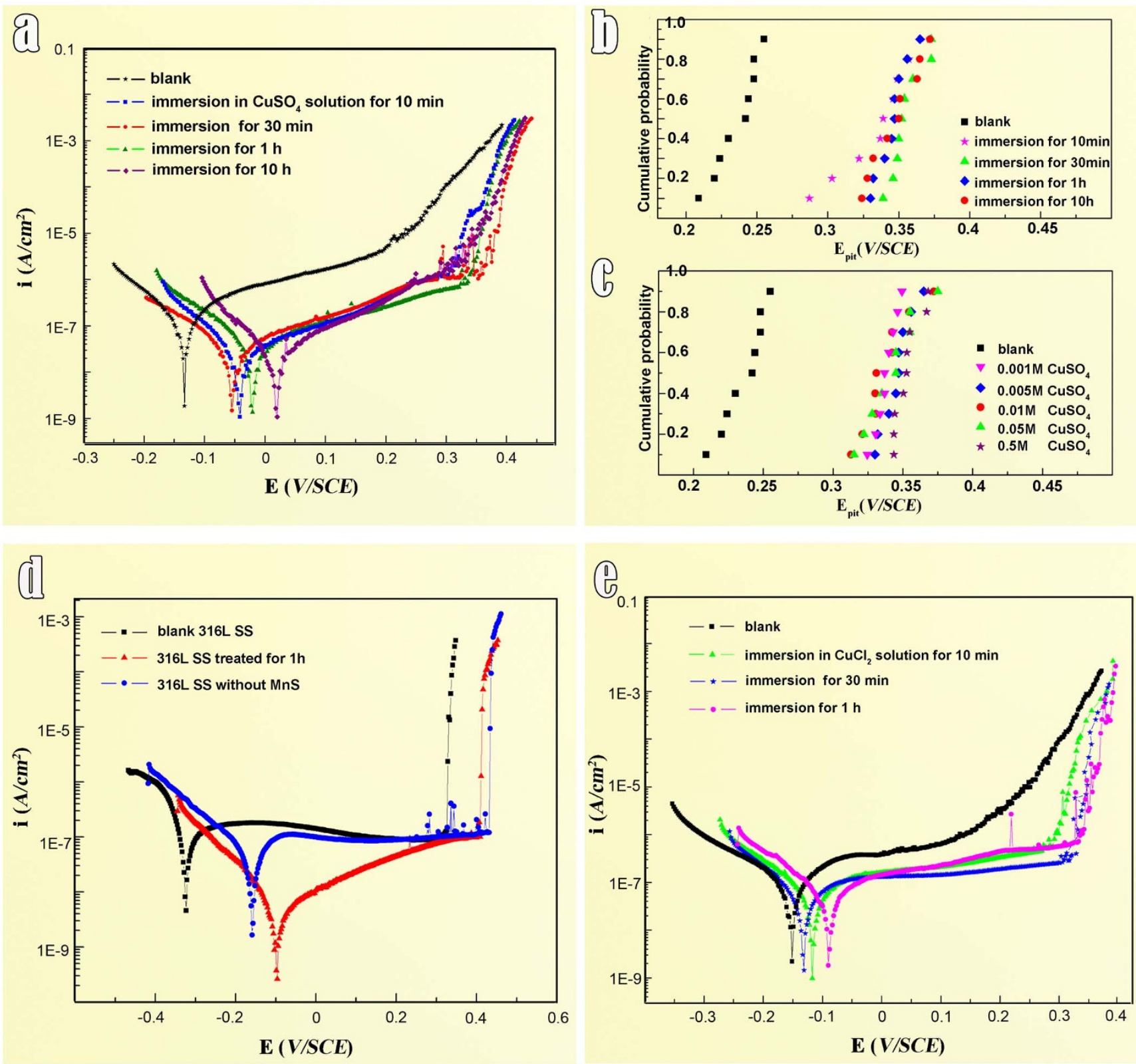

Figure 3 The potentiodynamic polarization tests and pitting potential distributions of the samples before and after chemical modification.

(a) Polarization curves of $316 \mathrm{~F} \mathrm{SS}$ samples before and after treatment for various periods in $0.005 \mathrm{M} \mathrm{CuSO}_{4}$ solution. (b) The distribution of pitting potential of 316F SS before and after treatment for various periods in $0.005 \mathrm{M} \mathrm{CuSO} 4$ solutions. It seems that the pitting potentials remain no much changes during the bathing duration from 0.5 to 10 hours. This indicates that bathing as short as 30 minutes in above solutions are effective enough to greatly improve the corrosion resistance of the present stainless steels. (c) The distribution of $E_{p i t}$ values of the samples treated in CuSO $\mathrm{O}_{4}$ solution with various concentrations for 1 hour. (d) Polarisation curves of 316L SS sample with MnS inclusion on surface before (black) and after treatment for one hour in $0.005 \mathrm{M} \mathrm{CuSO}_{4}$ solution (red). Corrosion behavior of the MnS-free 316L sample (blue) was also tested as comparison. Via chemical modification, the pitting potential of the treated 316L sample with MnS inclusions shifted to the same level as that of the MnS-free sample. (e) Polarisation curves of $316 \mathrm{~F}$ SS sample before and after the treatment for various periods in $0.003 \mathrm{M} \mathrm{CuCl}_{2}$ solution. The chemical modification in $\mathrm{CuCl}_{2}$ solution has the same beneficial effect on enhancing the pitting resistance of stainless steel as that in $\mathrm{CuSO}_{4}$ solution.

observed, respectively. Detailed analyses of chemical compositions onto a section of a MnS inclusion (marked in Fig. 6a) were performed, as shown in Fig. 6b. It is seen that, initially, $\mathrm{Cu}$ is not present in the MnS inclusion. However, the composition of the same MnS inclusion (shown in Fig. 6c) exhibits a remarkable change after the chemical modification (Fig. 6d). Most of the MnS is replaced by copper sulphide, especially in the area where specimen thickness is only several tens of nanometers. The detailed chemical compositions analysis by means of EDS line scanning was performed. Fig. 7 displays one example of EDS analysis, where a $\mathrm{MnCr}_{2} \mathrm{O}_{4}$ nano-particle is embedded in MnS medium in the HAADF image (Fig. 7a). The EDS profiles (Fig. $7 b-7 d$ ) are labeled which are obtained by linescanning along the red line in Fig. 7a. The intensity of $\mathrm{Cu}$-signal inside the inclusion gradually increases which suggests that the exchanged layer becomes thicker, with extending the immersion duration from 0 , to 10 minutes and 20 minutes. Both steel matrix and the $\mathrm{MnCr}_{2} \mathrm{O}_{4}$ particle inside the $\mathrm{MnS}$ inclusion were noticed to remain unchanged during the process of chemical modification.

Determined by HRTEM images along [001] and [1 $\overline{1} 0]$ directions (Fig. $8 \mathrm{a}$ and $8 \mathrm{~b}$, respectively), the final products has an isotypic 


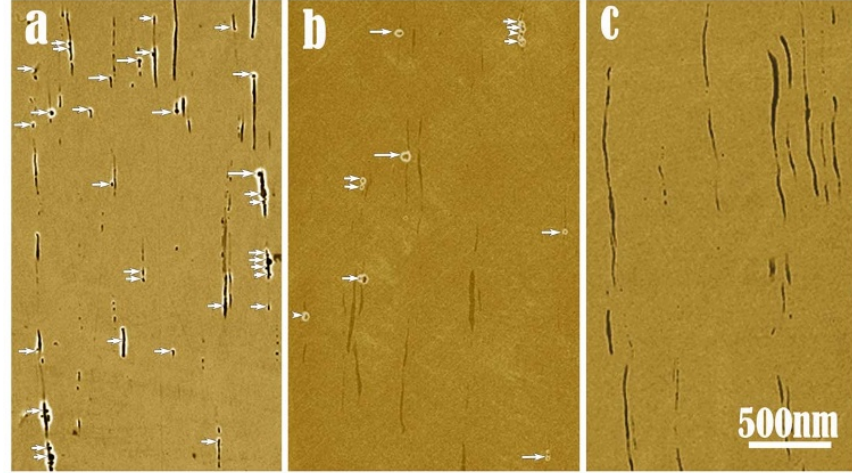

Figure 4 Typical SEM images of the samples suffered corrosion electrochemical tests in $0.5 \mathrm{M} \mathrm{NaCl}$ solution: (a) untreated sample, (b) sample with 10 minutes treatment in $0.005 \mathrm{M} \mathrm{CuSO}_{4}$ solution and (c) sample with 1 hour treatment in $0.005 \mathrm{M} \mathrm{CuSO}_{4}$ solution. The chemical modification via bathing the sample in $\mathrm{CuSO}_{4}$ solution greatly reduced the number of pits resulting from local dissolution of $\mathrm{MnS}$.

fluorite structure with lattice constant $a=0.54 \mathrm{~nm}$. A combination of lattice parameter and chemical compositions concludes that such a compound corresponds to $\mathrm{Cu}_{2-\delta} \mathrm{S}$, namely digenite, of a stoichiometry approaching to $\mathrm{Cu}_{1.8} \mathrm{~S}^{29}$. In such crystals, cations occupy the tetrahedral $8(\mathrm{c})$ sites and trigonal 32(f) sites randomly at room temperature. The crystal cells of cubic $\mathrm{MnS}$ and $\mathrm{Cu}_{2-\delta} \mathrm{S}$ are displayed in Fig. 8c.

The final product $\mathrm{Cu}_{2-\delta} \mathrm{S}$ indicates that both $\mathrm{Cu}^{+}$and $\mathrm{Cu}^{2+}$ are involved in the cation exchange process. The $\mathrm{Cu}^{+}$might be derived from the redox reaction between $\mathrm{Cu}^{2+}$ in $\mathrm{CuSO}_{4}$ eletrolyte and steel matrix. Although corrosion of stainless steels in dilute $\mathrm{CuSO}_{4}$ solution develops rather slowly ${ }^{30}$, it provides enough cuprous ions for the occurrence of cation exchange reaction at the free surfaces of $\mathrm{MnS}$ inclusions, since the area of the MnS inclusions is rather smaller compared with that of the whole steel surface. We propose the reaction pathway for the formation of $\mathrm{Cu}^{+}$be written as follows:

$$
\mathrm{Cu}^{2+}+\mathrm{Fe} \rightarrow \mathrm{Cu}+\mathrm{Fe}^{2+}
$$

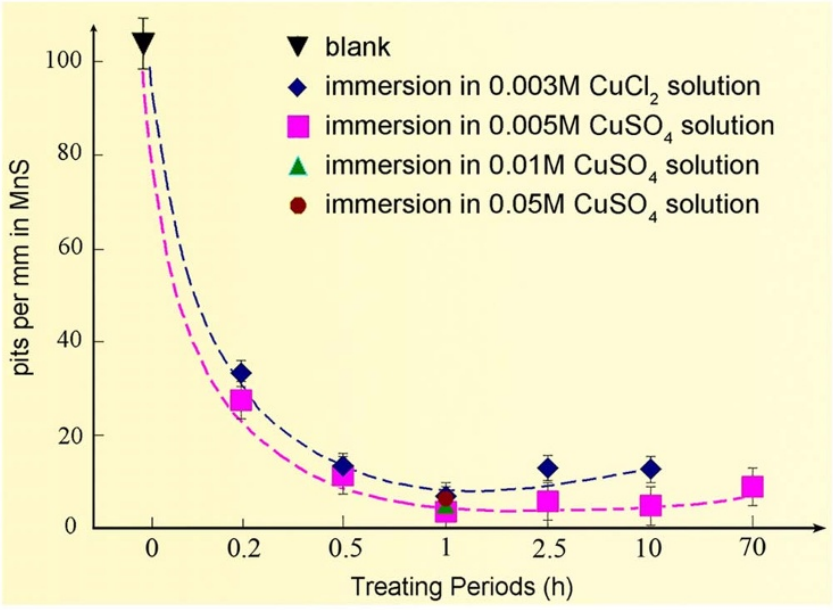

Figure 5 Statistical distributions of pits per unit length of $\mathrm{MnS}$ inclusion obtained from $>300$ inclusions on each sample surface. $\mathrm{CuSO}_{4}$ and $\mathrm{CuCl}_{2}$ solutions with various concentrations were used to bath the steel samples for variant durations. Whether $\mathrm{CuSO}_{4}$ or $\mathrm{CuCl}_{2}$ solution was applied, the numbers of the pits which results from the local dissolution of $\mathrm{MnS}$ are sharply reduced.

$$
\mathrm{Cu}+\mathrm{Cu}^{2+} \leftrightarrow \mathrm{Cu}^{+}
$$

Since cubic $\mathrm{Cu}_{2-\delta} \mathrm{S}$ and $\mathrm{MnS}$ share the same sub-lattice of $\mathrm{S}^{2-}$ anions and lattice constant of these two compounds are quite close, this enables the exchange between $\mathrm{Cu}^{+}$and $\mathrm{Mn}^{2+}$ through the frame of $\mathrm{S}^{2-}$ anions without rearrangement of $\mathrm{S}^{2-}$ lattices (see Fig. 8c). In this reaction, the large difference of solubility (solubility product $K_{\mathrm{MnS}}=10^{-13}, K_{\mathrm{Cu} 2 \mathrm{~S}}=10^{-48}$ ) provides the thermodynamic driving force for the spontaneous ions replacement ${ }^{26}$. The ideal reaction is demonstrated as follows:

$$
\mathrm{MnS}+2 \mathrm{Cu}^{+} \rightarrow \mathrm{Cu}_{2} \mathrm{~S}+\mathrm{Mn}^{2+}
$$

In the present study, the increase in pitting potential was attributed to the newly formed $\mathrm{Cu}_{2-\delta} S$ thin film which prevents the MnS from dissolution. In the galvanic system of $\mathrm{MnS} / \mathrm{MnCr}_{2} \mathrm{O}_{4}$, the potential difference between $\mathrm{MnS}$ dissolution $\left(E_{\mathrm{MnS}}\right)$ and oxygen reduction reaction $\left(E_{\mathrm{ORR}}\right)$ provides the thermodynamic driving force. Anode $\mathrm{MnS}$ tends to dissolve, while ORR takes place on the cathode $\mathrm{MnCr}_{2} \mathrm{O}_{4}$. Once the cation exchange occurs, the exposure layers of $\mathrm{MnS}$ are replaced by $\mathrm{Cu}_{2-\delta} \mathrm{S}$ which make the MnS be insulated from the solution. According to the E-pH diagram ${ }^{7,22}$, the equilibrium potential of $\mathrm{Cu}_{2-\delta} \mathrm{S}$ is much higher than that of $\mathrm{MnS}$ in a neutral environment and $\mathrm{Cu}_{2-\delta} \mathrm{S}$ can stably preserve in a wide range near $E_{\mathrm{ORR}}$, Therefore, the nano-galvanic cells was effectively invalided and the pitting potential of the alloy was enhanced by such a chemical decoration.

Ever since the MnS inclusion was identified as the initiation site for pitting corrosion, several methods have been tried in engineering to remove surface $\mathrm{MnS}$ inclusions, such as pickling, laser and high cur-
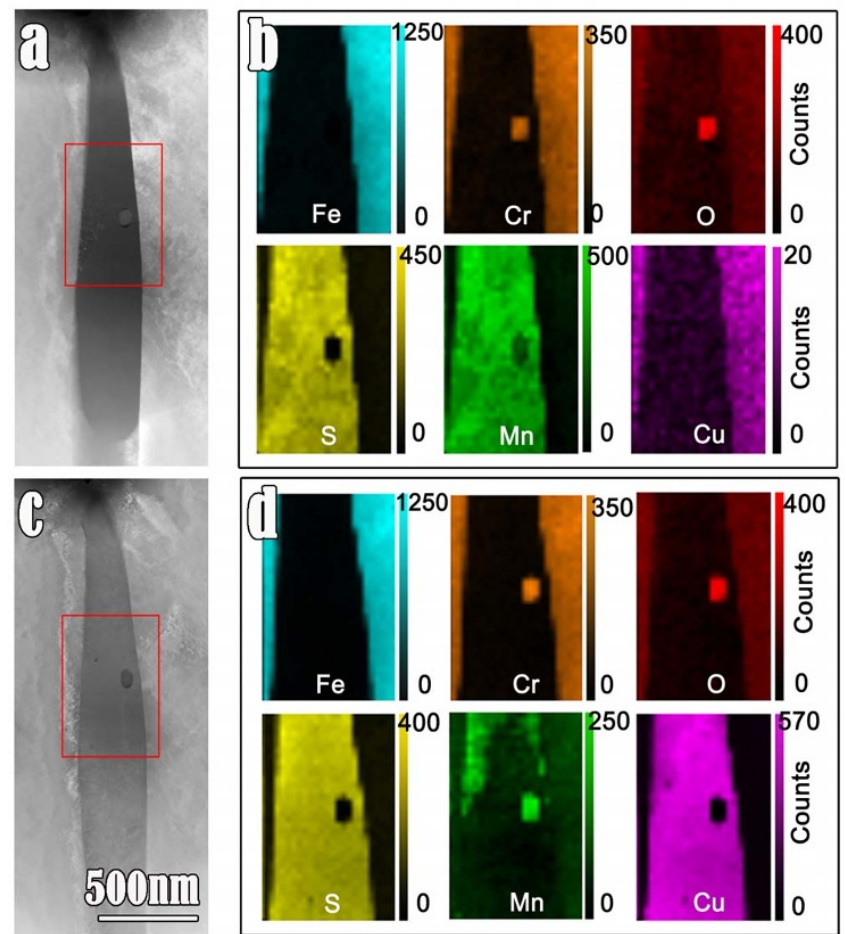

Figure 6 | Comparison of the chemical composition before and after treatment. (a) HAADF image showing the morphology of steel matrix, $\mathrm{MnS}$ inclusion, and a $\mathrm{MnCr}_{2} \mathrm{O}_{4}$ particle within MnS. (b) EDS elemental maps of the area marked with red tangle in (a). The counts level on the right side of each map was drawn from EDS profiles and used to semi-quantify the elements content. (c) HAADF image of the same section as that in (a) but suffered the treatment in $0.05 \mathrm{M} \mathrm{CuSO}_{4}$ solution for $20 \mathrm{~min}$. (d) EDS elemental maps of the area marked with red rectangle in (c). The MnS inclusion was almost transformed to copper sulphide. 

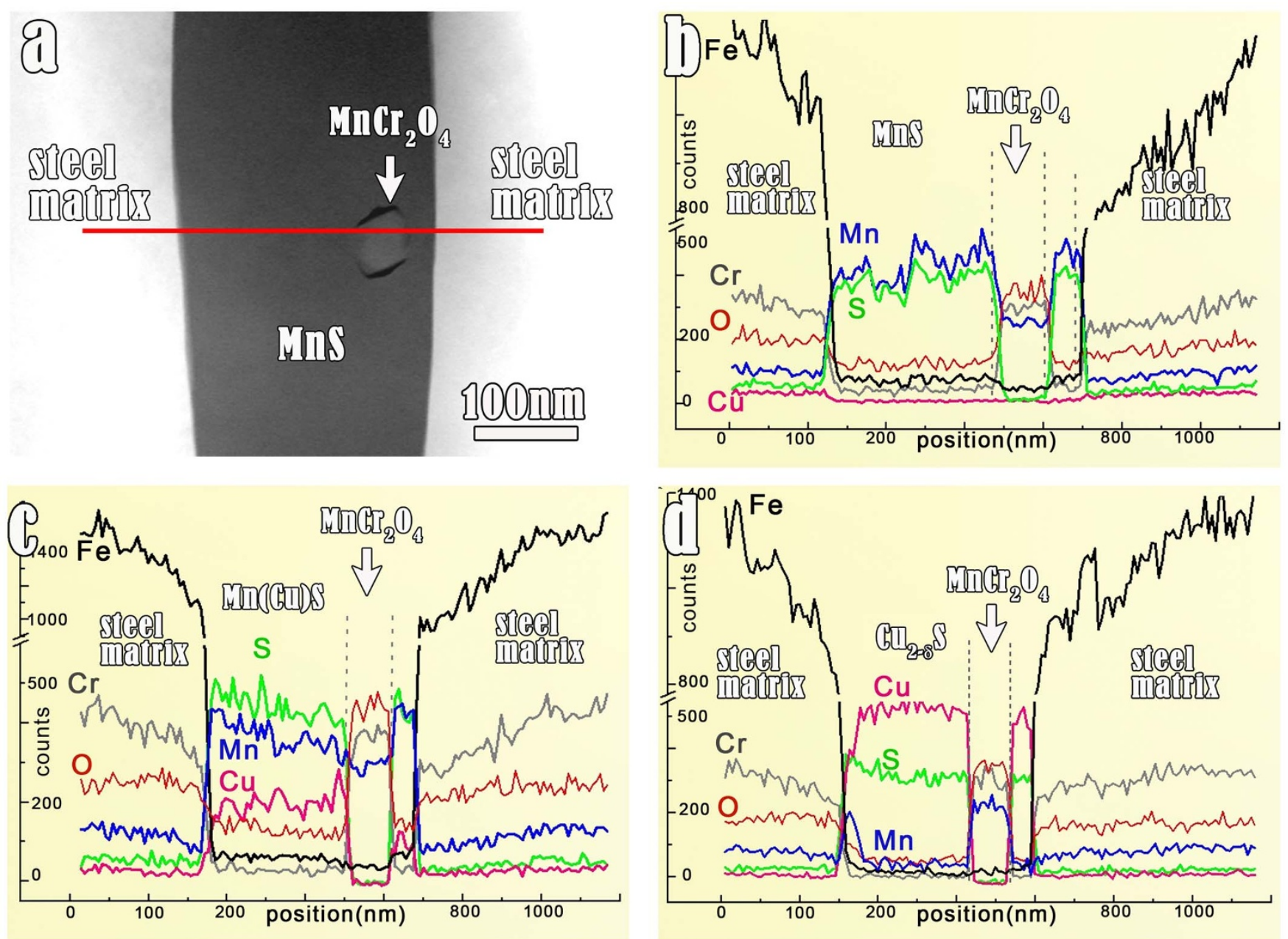

Figure 7 Analysis of composition evolvement in $\mathrm{MnS}$ versus variant durations of showering in the $0.05 \mathrm{M} \mathrm{CuSO}_{4}$ solution. A section of the sample is particularly focused. (a) HAADF image showing a MnS inclusion section with a $\mathrm{MnCr}_{2} \mathrm{O}_{4}$ particle therein. The horizontal red line marked in the image indicates the route along which chemical compositions are profiled. (b) The EDS profile of a scan made along the red line in (a). This profile corresponds to the chemical composition in the untreated sample. (c) EDS results along the same route but the sample experienced showering in $\mathrm{CuSO}_{4}$ solution for 10 minutes. Note that $\mathrm{Cu}$ signals get to appear in the "MnS inclusion". (d) EDS results along the same route but the sample experienced showering in CuSO 4 solution for 20 minutes. The intensity of $\mathrm{Mn}$ and $\mathrm{Cu}$ signals are reversed compared with that in (c) implying that most of $\mathrm{Mn}$ are replaced by $\mathrm{Cu}$.

rent beam modification. These approaches are useful but have considerable deficiencies. In contrast, the chemical modification via cation exchange reaction in the present study exhibits a much more feasible methodology to improve pitting corrosion resistance of stainless steels, since it is easy to operate for variant dimensions of components. Hence, this study provides a low-cost approach via an atomic scale decoration to improve the corrosion resistance of steels in a volumetreated manner, and has a great signification in improving the integrated properties of stainless steels serving in wet environments.

\section{Methods}

Bulk sample preparation. Commercial 316F type stainless steel with high-sulphur content $(0.16 \%)$ was chosen because it can provide a large number of MnS inclusions for analysis. The steel was made by Nippon Steel and Sumikin Stainless Steel Corporation. 316L type stainless steel was made by Baosteel Corporation in Shanghai, China.

The hot-rolled steel rod was cut into sheets with the same size along the rolling direction. The samples were carefully polished with standard $\mathrm{SiC}$ grinding papers. The samples were then lightly polished using $1 \mu \mathrm{m}$ diamond paste until there was no visible scratch on the surfaces. After exposure in air for 12 hours, the samples were immersed in a $\mathrm{Cu}$-containing solution at room temperature for different periods. Those treated samples were cleaned by distilled water and dried for the subsequent electrochemical tests and other structural characterization (SEM, EPMA).

TEM sample preparation. The samples cut from the steel rod were ground using variant grit silicon carbide papers, polished with diamond paste, and finally thinned by ion-milling. After the first-round TEM observation, some of the specimens were plasma-cleaned and then immersed into $1 \mathrm{~mol} / \mathrm{L} \mathrm{NaCl}$ solution for immersioncorrosion test. The TEM specimens after immersion were quickly cleaned in distilled water and methanol, dried, and transferred into the TEM for further investigation.

The plan-view TEM samples for analyzing the structural and chemical information of $\mathrm{Cu}_{2-\delta} \mathrm{S}$ were prepared by ion-milling and treated in $0.05 \mathrm{~mol} / \mathrm{L} \mathrm{CuSO}_{4}$ solution at room temperature after first-round TEM observation.

The cross-sectional sample, used for determining the thickness of reaction layer, was prepared by the conventional methods. Two pieces of $316 \mathrm{~F}$ stainless steel samples with polished surfaces were immersed in $0.05 \mathrm{~mol} / \mathrm{L} \mathrm{CuSO}_{4}$ solution for 1 hour. The treated surfaces of two samples were bonded face-to-face and then thinned by grinding, dimpling and ion-milling.

TEM, SEM and EPMA characterizations. A Tecnai $\mathrm{G}^{2}$ F30 transmission electron microscope, equipped with HAADF detector and X-ray dispersive spectrometer systems, was used at $300 \mathrm{kV}$ for diffraction, HAADF imaging, composition analysis, and $3 \mathrm{D}$ tomography. Microstructure characterizations of $\mathrm{Cu}_{2-\delta} \mathrm{S}$ were performed using a Titan $\mathrm{G}^{2}$ 60-300 TEM equipped with double spherical aberration (Cs) correctors. A SUPRA35 field emission scanning electron microscope was used to investigate the morphology of MnS inclusions. The surface composition of the bulk materials was analyzed using an electron probe X-ray microanalyzer (EPMA: Shimazu Seisakusho EPMA-1610).

Electrochemical test procedures. A traditional three-electrode system was used in electrochemical experiment. The working electrode is stainless steel specimen, $\mathrm{Pt}$ counter electrode and SCE (saturated with $\mathrm{KCl}$ ) reference electrode. AUTOLAB PGSTAT302N electrochemical workstation was used in potentiodynamic polarization curve measurements with a scan rate $1 \mathrm{mV} / \mathrm{s}$. All the tests were stopped when the 

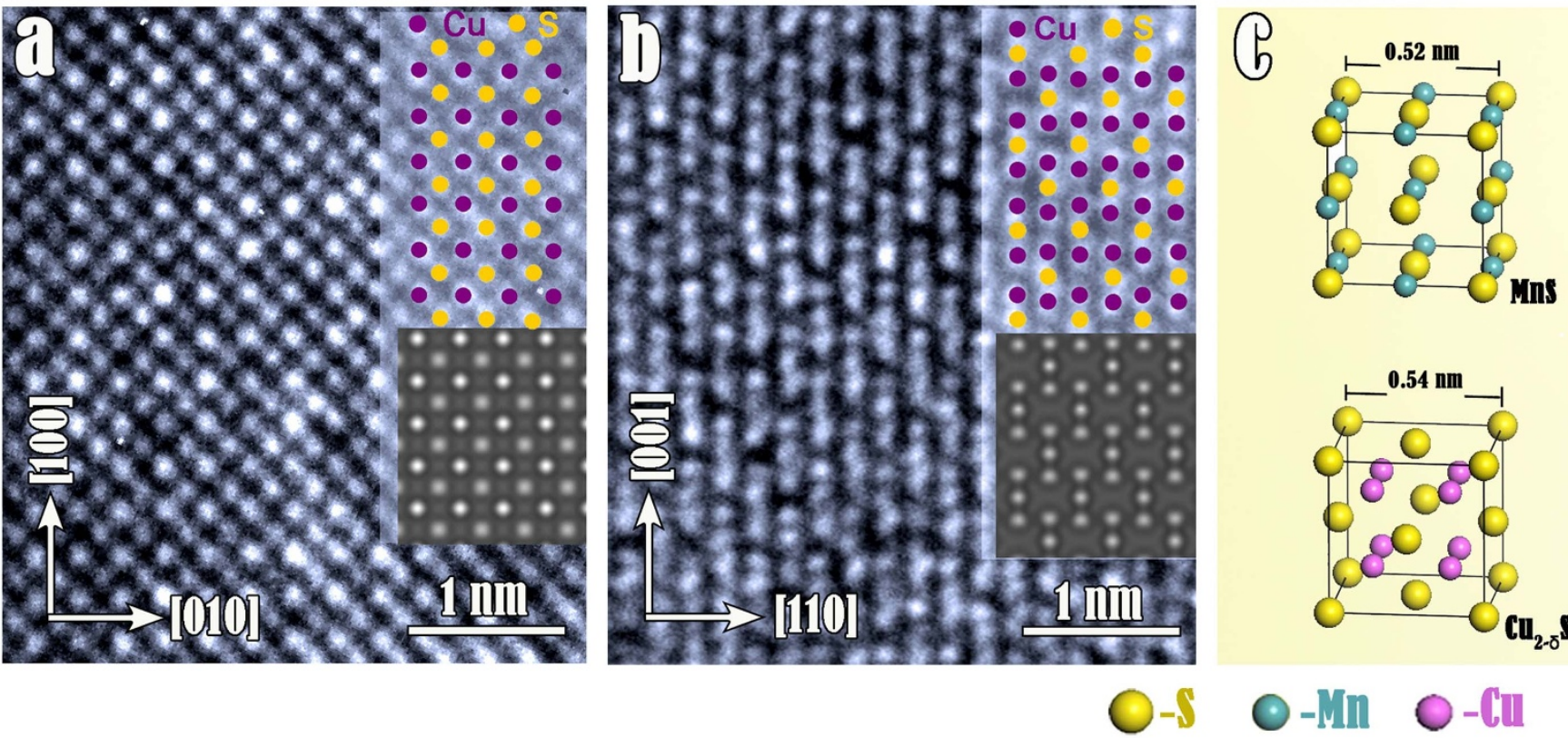

Figure 8 Identification of the product after the cation exchange reaction by aberration-corrected high-resolution transmission electron microscope. (a) HRTEM image along [001] direction of $\mathrm{Cu}_{2-\delta} \mathrm{S}$. The projection of the structure along [001] is superimposed on the image. The simulated image of the structure is shown as an inset with a thickness of $5.4 \mathrm{~nm}$. Note that the copper columns in the image show brighter contrast in the image. (b) HRTEM image taken along $[1 \overline{1} 0]$ direction of $\mathrm{Cu}_{2-\delta} \mathrm{S}$. Atomic projection and simulated images are shown as insets. (c) The crystal cells of cubic $\mathrm{MnS}$ and $\mathrm{Cu}_{2-\delta} \mathrm{S}$. These two compounds share the same sub-lattice of $S^{2-}$ anions and the lattice constant of them are rather close.

anodic current density reached the value of $1 \mathrm{~mA} / \mathrm{cm}^{2}$. The tested solution of $0.5 \mathrm{~mol} / \mathrm{L}$ $\mathrm{NaCl}$ electrolytes was maintained at $28^{\circ} \mathrm{C}$ with electric-heated thermostatic water bath. The potentiodynamic polarization curve includes the cathodic and anodic branches. In the anodic branch, there exists a well-defined inflexion, above which anodic current density sharply increase with potential, meaning stable pitting corrosion occurs. The potential value corresponding to that inflexion is identified as pitting potential $\left(E_{\mathrm{pit}}\right)$.

1. Lyon, S. Materials science - A natural solution to corrosion? Nature 427, 406-407 (2004).

2. Williams, D. E., Newman, R. C., Song, Q. \& Kelly, R. G. Passivity breakdown and pitting corrosion of binary-alloys. Nature 350, 216-219 (1991).

3. Punckt, C. et al. Sudden onset of pitting corrosion on stainless steel as a critical phenomenon. Science 305, 1133-1136 (2004).

4. Jones, R. L. Some critical corrosion issues and mitigation strategies affecting light water reactors. Mater. Perform. 35, 63-67 (1996).

5. Frankel, G. S. Pitting Corrosion of Metals: A Review of the Critical Factors. J. Electrochem. Soc. 145, 2186-2198 (1998).

6. Shaw, M. C., Cook, N. H. \& Smith, P. A. Free Machining Steel: I-Tool-Life Characteristics of Resulfurized Steel. J. Eng. for Industry. 83, 163-172 (1961)

7. Eklund, G. S. Initiation of pitting at sulfide inclusions in stainless steel. J. Electrochem. Soc. 121, 467-473 (1974).

8. Wranglen, G. Pitting and sulphide inclusions in steel. Corros. Sci. 14, 331-349 (1974).

9. Castle, J. E. \& Ke, R. Studies by Auger Spectroscopy of pit initiation at the site of inclusions in stainless-steel. Corros. Sci. 30, 409-428 (1990).

10. Stewart, J. \& Williams, D. E. The Initiation of Pitting Corrosion on Austenitic Stainless-Steel: on the Role and Importance of Sulfide Inclusions. Corros. Sci. 33, 457-474 (1992)

11. Webb, E. G. \& Alkire, R. C. Pit initiation at single sulfide inclusions in stainless steel - I. Electrochemical microcell measurement. J. Electrochem. Soc. 149, B272-B279 (2002)

12. Zheng, S. J. et al. Identification of $\mathrm{MnCr}_{2} \mathrm{O}_{4}$ nano-octahedron in catalysing pitting corrosion of austenitic stainless steels. Acta Mater. 58, 5070-5085 (2010).

13. Wang, Y. J., Hu, P. \& Ma, X. L. Oxygen reduction reaction on metal-terminated $\mathrm{MnCr}_{2} \mathrm{O}_{4}$ nano-octahedron catalyzing $\mathrm{MnS}$ dissolution in an austenitic stainless steel. J. Phys. Chem. C. 115, 4127-4133 (2011).

14. Amri, J., Souier, T., Malki, B. \& Baroux, B. Effect of the final annealing of cold rolled stainless steels sheets on the electronic properties and pit nucleation resistance of passive films. Corros. Sci. 50, 431-435 (2008).

15. Barbosa, M. A. The pitting resistance of AISI 316 stainless steel passivated in diluted nitric acid. Corros. Sci. 23, 1293-1305 (1983).

16. Noh, J. S., Laycock, N. J., Gao, W. \&Wells, D. B. Effects of nitric acid passivation on the pitting resistance of 316 stainless steel. Corros. Sci. 42, 2069-2084 (2000).
17. Kamachi Mudali, U., Dayal, R. K., Gnanamoorhy, J. B., Kanetkar, S. M. \& Ogale, S. B. Localized corrosion studied on laser surface melted type 316 austenite stainless steels. Mater. Trans. JIM. 33, 845-853 (1991).

18. Zhang, K. M., Zou, J. X., Grosdidier, T., Dong, C. \& Yang, D. Z. Improved pitting corrosion resistance of AISI 316L stainless steel treated by high current pulsed electron beam. Surf. Coat. Technol. 201, 1393-1400 (2006).

19. Williams, D. E., Kilburn, M. R., Cliff, J. \& Waterhouse, G. I. N. Composition changes around sulphide inclusions in stainless steels, and implications for the initiation of pitting corrosion. Corros. Sci. 52, 3702-3716 (2010).

20. Degerbeck, J. Influence of Mn compared to that of $\mathrm{Cr}$, Mo and S on resistance to initiation of pitting and crevice corrosion in austenitic stainless steels. Mater. Corros. 29, 179-188 (1978).

21. Williams, D. E., Mohiuddin, T. F. \& Zhu, Y. Y. Elucidation of a trigger mechanism for pitting corrosion of stainless steels using submicron resolution scanning electrochemical and photoelectrochemical microscopy. J. Electrochem. Soc. 145, 2664-2672 (1998).

22. Sourisseau, T., Chauveau, E. \& Baroux, B. Mechanism of copper action on pitting phenomena observed on stainless steels in chloride media. Corros. Sci. 47, 1097-1117 (2005)

23. Son, D. H., Hughes, S. M., Yin, Y. D. \& Alivisatos1, A. P. Cation exchange reactions in ionic crystals. Science. 306, 1009-1012 (2004).

24. Robinson, R. D. et al. Spontaneous superlattice formation in nanorods through partial cation exchange. Science. 317, 355-358 (2007).

25. Camargo, P. H. C., Lee, Y. H., Jeong, U., Zou, Z. Q. \& Xia, Y. N. Cation exchange: a simple and versatile route to inorganic colloidal spheres with the same size but different compositions and properties. Langmuir. 23, 2985-2992 (2007).

26. Xu, G., Zhu, Y. L. \& Ma, X. L. $\mathrm{Cu}_{2} \mathrm{~S}$ nanowires and $\mathrm{MnS} / \mathrm{Cu}_{2} \mathrm{~S}$ nanojunctions derived from $\gamma$-MnS nanowires via selective cation-exchange reaction. Phys. Status. Solidi. A. 208, 123-128 (2011).

27. Pennycook, S. J. Structure determination through Z-contrast microscopy. Adv. Imag. Electron Phys. 123, 173-206 (2002).

28. Goodhew, P. J., Humphreys, J. \& Beanland, R. Electron microscopy and analysis. $3^{\text {rd }}$ edition. London: Taylor and Francis. (2001).

29. Yamamoto, K. \& Kashida, S. X-ray study on the average structure of $\mathrm{Cu}_{2} \mathrm{Se}$ and $\mathrm{Cu}_{1.8} \mathrm{~S}$ in the room temperature and the high temperature phases. J. Solid. State Chem. 93, 202-211 (1991).

30. De Renzo, D. J. (Ed.) Corrosion resistant materials handbook. $4^{\text {th }}$ edition. New Jersey: William Andrew Publishing /Noyes. (1985).

\section{Acknowledgments}

We are grateful to Prof. T. Zhang and Dr. Y. J. Wang in Institute of Metal Research for helpful discussion. This work is supported by the National Natural Foundation of China (51101157) and Ministry of Science \& Technology of China (2009CB623705). 


\section{Author contributions}

This project was conceived by X.L.M.; TEM experiments were performed by Y.T.Z., B.Z. and S.J.Z.; electrochemical experiments were carried out by B.Z., Y.T.Z., J.W. and X.Y.S.; all the authors participated in discussion, interpretation of the data, and producing the final version of this paper.

\section{Additional information}

Competing financial interests: The authors declare no competing financial interests.

How to cite this article: Zhou, Y.T. et al. Atomic-scale decoration for improving the pitting corrosion resistance of austenitic stainless steels. Sci. Rep. 4, 3604; DOI:10.1038/srep03604 (2014).

(c) (1)

This work is licensed under a Creative Commons Attribution 3.0 Unported license.

To view a copy of this license, visit http://creativecommons.org/licenses/by/3.0 